\title{
DIVERSIDADE E INCLUSÃO SOCIAL: UMA ABOR- DAGEM NO CENÁRIO ORGANIZACIONAL
}

\author{
DIVERSITY AND SOCIAL INCLUSION: AN APPRO- \\ ACH IN THE ORGANIZATIONAL SCENARIO
}

Suellen Cristina Ribeiro Akamine ${ }^{1}$

Resumo: A diversidade refere-se às particularidades humanas, as quais tornam os indivíduos diferentes uns dos outros, sendo considerado, atualmente, um desafio importante e complexo às organizações. A empresa precisa entender a diversidade, permitindo que a organização seja cuidadosa em conduzir as diferenças contextuais, e utilizá-la como alavanca para a vantagem competitiva, reduzindo possíveis impactos negativos que possam surgir a partir dessa heterogeneidade. Esse estudo foi realizado através de revisão de literatura em Artigos e outros textos. O objetivo desse artigo foi abordar aspectos da diversidade e inclusão social no cenário organizacional. Os resultados observados, por meio dos estudos bibliográficos foram a importância do respeito à diversidade e inclusão voltadas para o ambiente de trabalho, valorizando o potencial e o talento de cada indivíduo, tornando um

1 Graduada em Fonoaudiologia pela Universidade Católica Dom Bosco. Especialista em Gestão de Saúde Pública pela Universidade Unigran. Especialista em Atenção Básica em Saúde da Família pela FIOCRUZ e UFMS. Especialista em Fonoaudiologia Hospitalar e Disfagias Orofaríngeas pela FAMOSP. Especialista em Psicopedagogia pela Universidade UNAES Anhanguer

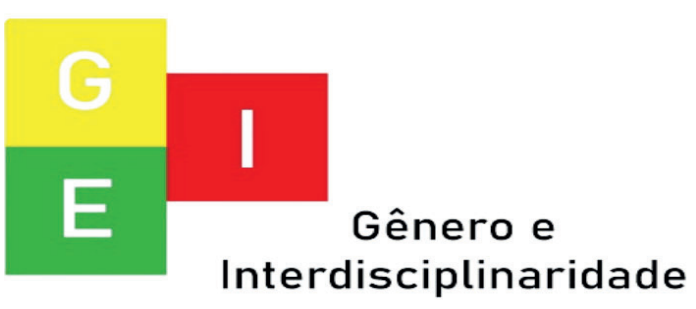


ISSN: 2675-7451

Vol. 02 - n 03 - ano 2021

Editora Acadêmica Periodicojs

ambiente acolhedor e produtivo. it as a lever for competitive ad-

Concluiu-se que as organizações que optam por políticas que respeitam a diversidade, tratando de forma justa e sem discriminação, valorizando os talentos, ideias e formas diferentes de pensar de cada indivíduo, possibilitam maneiras de complementar os saberes dentro do grupo, possibilitando alcançar o sucesso dentro da organização.

Palavras - chave: Diversidade cultural, inclusão e organização.

Abstract: Diversity refers to human particularities, which make individuals different from each other, and is currently considered an important and complex challenge for organizations. The company needs to understand diversity, allowing the organization to be careful in driving contextual differences, and to use vantage, reducing possible negative impacts that may arise from this heterogeneity. This study was carried out through a literature review in Articles and other texts. The purpose of this article was to address aspects of diversity and social inclusion in the organizational scenario. The results observed through bibliographic studies were the importance of respecting diversity and inclusion aimed at the work environment, valuing the potential and talent of each individual, making it a welcoming and productive environment. It was concluded that organizations that choose policies that respect diversity, treating fairly and without discrimination, valuing the talents, ideas and different ways of thinking of each individual, enable ways to complement the knowledge within the group, making it possi-

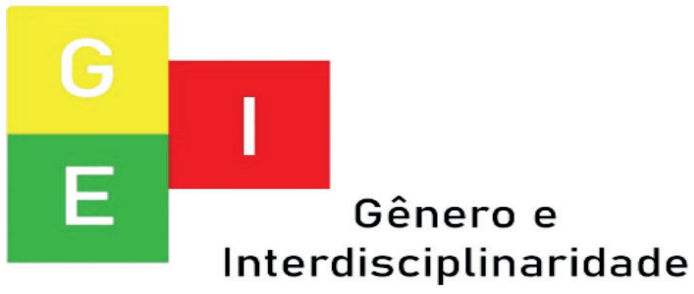


ISSN: 2675-7451

Vol. 02 - n 03 - ano 2021

Editora Acadêmica Periodicojs

ble to achieve success within the organization.

Keywords: Diversity, inclusion e organization.

\section{INTRODUÇÃO}

A diversidade tem se consolidado na pauta empresarial em todo o mundo, principalmente em razão das diferenças na força de trabalho. Aspectos como gênero, etnia, orientação sexual, idade, crença religiosa ou limitações físicas, por exemplo, assinalam a heterogeneidade, demandando práticas que harmonizem lucro e justiça social. A partir da década de 1980, a diversidade emergiu como um dos mais profícuos temas em estudos organizacionais, em parte pela perspectiva de que a inclusão de minorias historicamente discriminadas melhoraria o ambiente de trabalho, tornando-o mais diversificado e democrático, mas como tratar diferentes com igualdade?

Em relação à diversidade, os discursos são particularmente ambíguos. Em busca de legitimidade social, ao investir em práticas não discriminatórias, as organizações se habilitam a ser percebidas como mais socialmente responsáveis do que outras que não adotem a mesma postura. Contudo, são de se considerar a efetividade e os desdobramentos dos discursos empresariais pró-diversidade. A efetividade se refere à intensidade com que são praticadas as políticas de igualdade de oportunidades entre indivíduos de segmentos socialmente discriminados. Os desdobramentos são um efeito da adoção ou não de tais medidas, pois a legitimidade é ameaçada quando os indivíduos não acre-

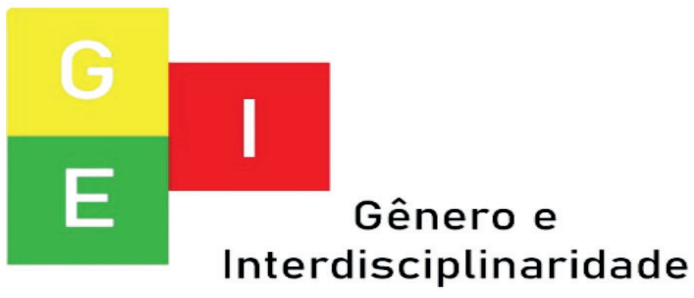


ISSN: 2675-7451

Vol. 02 - n 03 - ano 2021

Editora Acadêmica Periodicojs

ditam nas políticas pela ausência de oportunidades de ascensão e de reconhecimento.

O papel gerencial na promoção da diversidade e inclusão é explícito no fragmento discursivo: criar um "melhor ambiente de trabalho", sugerindo preocupação com a ausência de empecilhos ao alcance de resultados. O implícito pressuposto é que a diversidade é tratada como um problema potencial, resolvido com a inclusão de minorias. Os gerentes, assim, devem se somar “às políticas da companhia e políticas e práticas locais no seu negócio e região" e isso "inclui entender, apropriar-se e comunicar conceitos chave em mensagens dirigidas aos empregados", o que significa se familiarizarem "com os principais temas/objetivos e envolvimento com planos de ação para alcançar objetivos”. Isso os habilita a serem percebidos como líderes por desempenhar um papel ativo na manutenção de um ambiente de trabalho que promova "dignidade, cortesia, e respeito pelo indivíduo". Também ao “prover acomodação razoável para empregados com deficiência" e apoiar as políticas da empresa com "comprometimento da companhia com pequenos negócios de propriedade ou operação de mulheres, pessoas de cor e pessoas com deficiência”.

Vale ressaltar que a trabalhadora que é mãe e amamenta também deve ser acolhida de forma responsável e adequada no ambiente de trabalho, por isso tanto as organizações públicas quanto as privadas, devem implementar políticas e práticas que facilitam o processo de amamentação. Hoje ainda existem empresas que adotam a licença maternidade por apenas quatro meses e a recomendação da OMS é do

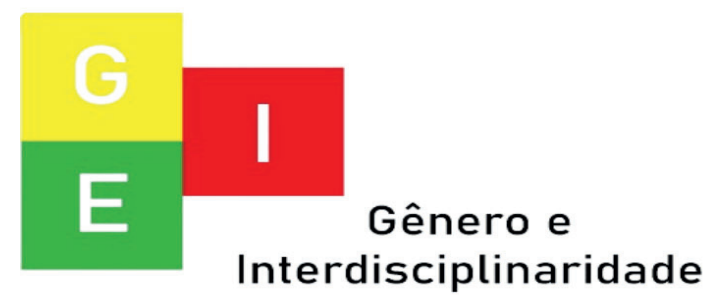


ISSN: 2675-7451

Vol. 02 - n 03 - ano 2021

Editora Acadêmica Periodicojs

aleitamento materno exclusivo por seis meses, tornando inviável a volta da mãe para o trabalho, e mesmo após os seis meses de licença maternidade oferecido por algumas empresas, ainda sim ao retornarem ao trabalho as mães acabam desistindo de amamentar ou mesmo desistindo de trabalhar fora de casa por não ter flexibilidade dentro da empresa.

Na Semana Mundial do Aleitamento Materno, a OPAS insta os governos, doadores e outros responsáveis pela tomada de decisões e para adotar medidas firmes para proteger, promover e apoiar a amamentação. Aplicar uma política de direitos da maternidade, que a proteja alinhada à Convenção e recomendação da Organização Internacional do Trabalho a (OIT), assim como oferecer apoio e aconselhamento especializado às mães.

A cultura dentro das or- ganizações surge de duas formas: pela vontade dos proprietários e pela interação diária dos funcionários que as integram. Pode, ainda, a cultura organizacional ser decorrente da cultura constituída na sociedade na qual está inserida, "o que permite identificar outro processo de formação das culturas organizacionais, como decorrentes das necessidades da sociedade", a cultura organizacional é uma forma ou conjunto de representações mentais, como um complexo de saberes. Seria como um "elo" que une todos os membros aos mesmos objetivos. Além disso, serve como chave para distinguir a coletividade, fazendo com que os colaboradores pensem e ajam de modos parecidos.

A gestão da diversidade nas organizações apresenta muitos benefícios, desde a atração de talentos, assim como a conquista

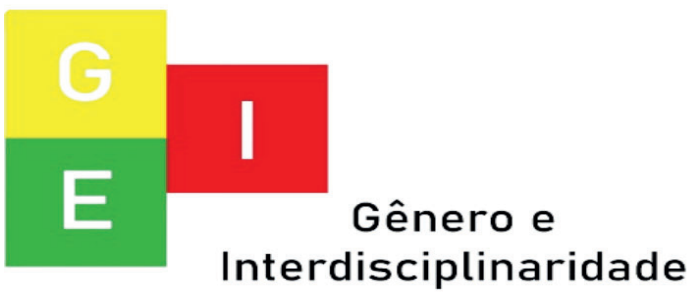


ISSN: 2675-7451

Vol. 02 - n 03 - ano 2021

Editora Acadêmica Periodicojs

de mercados em diferentes segmentos, o incentivo à solução de problemas, tomada de decisão e a flexibilidade organizacional, porém ainda não são todas as organizações que aderem a esse modelo de gestão.

\section{DESENVOLVIMENTO}

Tendo em vista a globalização, a competitividade é inevitável, o que faz com que as empresas repensem suas maneiras de conduzir os negócios. O ser humano sabe administrar seus limites, negociar espaços, construir alianças, corromper autoridade e criar alternativas buscando atingir seus interesses, ao mesmo tempo em que as organizações procuram atingir seus objetivos. Em meio a isso, deve haver um equilíbrio de interesses, aos colaboradores, satisfação por meio de suas necessidades psicológicas, envolvendo-os com mais motivação ao trabalho, e, para a entidade, aumento na produtividade. Dessa forma observa-se a relevância das pessoas e de sua gestão, por meio de políticas eficazes para a organização, respeitando a cultura individual e a cultura da entidade, ajudando a entender o conflito dos mais variados grupos e o conflito no nível organizacional.

A diversidade cultural (re)configura a ética como condição adaptativa das relações humanas na sociedade atual. O equilíbrio entre ética, estética e técnica serve para intermediar a vida mediante os parâmetros providenciais do respeito e da dignidade humana. Diante do "novo - outros" contornos, tal diversidade instaura um posicionamento crítico e, ao mesmo tempo, flexível sobre aspectos econômicos, identitários e so-

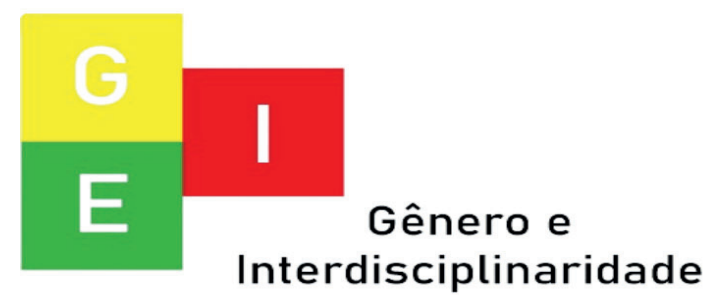


ISSN: 2675-7451

Vol. 02 - n 03 - ano 2021

Editora Acadêmica Periodicojs

cioculturais, os quais entrelaçam um sistema de (re)apropriações e trocas culturais. A partir da diversidade, proliferam-se vozes destoantes do sistema hegemônico na perspectiva periférica das culturas minoritárias: mulheres, homossexuais, negros/as, índios/ as, idosos/as, deficientes físicos entre outras. A expectativa dessas minorias seria buscar alternativas para criar "novo - outros", visando algo consistente capaz de emponderar discursos e ações efetivas, com atitude robusta.

A diversidade cultural se apresenta hoje como uma das questões mais importantes no campo da educação e no contexto mais amplo da sociedade. A diversidade cultural se caracteriza por práticas e produções culturais desenvolvidas por grupos e coletivos, mas também por indivíduos que a expressam de forma singular.
"As fronteiras sociais e

culturais têm uma coincidência cada vez menores", já que, contemporaneamente, a diversidade cultural está cada vez mais dentro das próprias sociedades, fazendo com que o confronto e as trocas sejam muito mais presentes nos processos da renovação cultural do que o foram no passado. Essa situação na qual os outros já não se apresentam distantes como anteriormente e seus modos de ser e viver se desenvolvem cada vez mais conectando aos mais variados estilos de vida, criando uma série de novos desafios, ou seja, a globalização cada vez mais vem ganhando espaço e notoriedade no cenário atual.

Não obstante o que já se pode acumular como crítica ao etnocentrismo e seus efeitos deletérios, viver a vida cotidiana em meio à diversidade exige dos indivíduos e grupos sociais

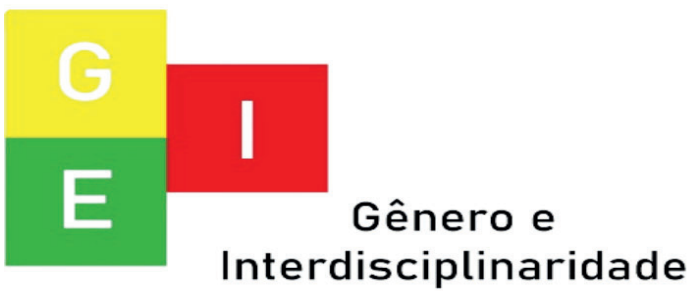


ISSN: 2675-7451

Vol. 02 - n 03 - ano 2021

Editora Acadêmica Periodicojs

a constante afirmação e reafirmação de valores e juízos morais referentes a nós e aos outros. Isso pode possibilitar um reexame do etnocentrismo que acaba por reconhecê-lo como portador de virtudes, tendo por base subjacente uma ideia de que a celebração das diferenças e a empatia a elas reduziriam, ou mesmo eliminariam, nossa capacidade de julgar tomando por base nossa própria cultura, à qual não podemos renunciar, ou seja, seriam justificáveis certas doses de etnocentrismo para se conter o risco de uma entropia moral.

A gestão da diversidade tornou-se um tema com ampla relevância para as empresas. Nesse sentido, tem ganhado cada vez mais profundidade para problematizar a contemporaneidade das relações no mundo do traba1ho. Segundo (Alves et.al., 2004) a gestão da diversidade apresen- ta-se sob duas principais perspectivas: a primeira refere-se à eficácia da gestão da diversidade em oposição o papel do Estado que garante através de ações afirmativas a superação das desigualdades sociais destinadas a determinados grupos sociais e, segundo, a gestão da diversidade tomada como vantagem competitiva a fim de gerar ganhos de mercado em face da sua representatividade multicultural.

Assim sendo, tal contexto assenta a gestão da diversidade numa dicotomia segundo (Alves et.al., 2004). Deste modo, seus conceitos e práticas são tomados como positivos na busca por equidade no acesso ao mercado de trabalho e como vantagem competitiva para as empresas. De modo paralelo, articula-se a legitimação permanente dessas desigualdades à medida que tal modelo encontra-se condicio-

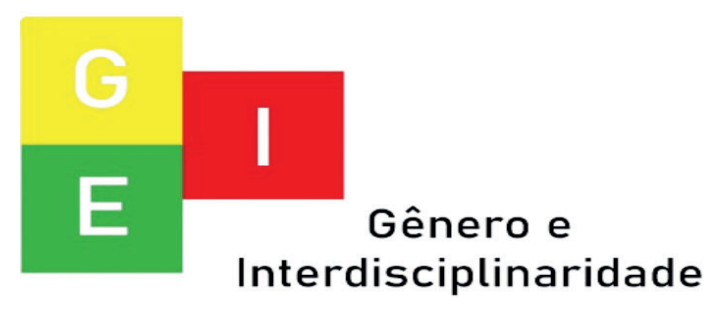


ISSN: 2675-7451

Vol. 02 - n 03 - ano 2021

Editora Acadêmica Periodicojs

nado a existência de práticas de discriminação e marginalização que, conforme (Sawaia, 2001) constitui a lógica dialética da exclusão/inclusão.

Por outro lado, para (Hammes, et.al. 2015) dialogar a respeito das diferenças humanas no dia- a-dia das empresas é essencial. Para tanto, é necessário que as empresas reconheçam de fato que diversidade entre as pessoas é uma dimensão favorável. A partir desse olhar, é possível pensar em empresas realmente comprometidas e contribuindo com os avanços a favor de uma sociedade mais justa a todos.

A gestão da diversidade faz-se necessária para aproveitar o melhor de cada região. Conforme (Vils, 2001) a gestão da diversidade é um processo poderoso para o crescimento da empresa, como ouvir as opiniões, conhecer as culturas, a maneira e caracte- rísticas de cada um no trabalho, não existindo um modelo, algo inquestionável, com o qual todos concordem. Querem-se pessoas participativas, com ideias e atitudes proativas.

Minoria pode ser entendida como um grupo, numericamente menor ou não, que possui uma diferença de oportunidades em relação ao outro grupo. Diferenças essas que no contexto em que estão inseridas geram barreiras que impedem este grupo de desfrutar de cotidianos sociais, como por exemplo, a atuação no mercado de trabalho, de acordo com (Ribeiro, 2007). Desse grupo são: negros, pessoas com deficiência, mulheres, homossexuais e indígenas.

A inclusão social, tema recorrente e afim ao deste trabalho, "está relacionada com a procura de estabilidade social através da cidadania social, ou seja,

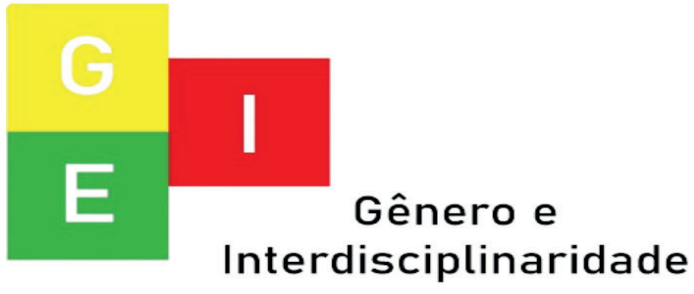


ISSN: 2675-7451

Vol. 02 - n 03 - ano 2021

Editora Acadêmica Periodicojs

todos os cidadãos têm os mesmos direitos na sociedade" (Sheppard, 2006) e se mostra um conceito intimamente relacionado ao de gestão da diversidade quando compreendemos os elementos que a caracterizam, são: "Valorização das pessoas e grupos independentes de religião, etnia, gênero ou diferença de idade; estruturas que possibilite possibilidades de escolhas; envolvimento nas decisões que afetam a si em qualquer escala; disponibilidade de oportunidades e recursos necessários para que todos possam participar plenamente na sociedade".

É de extrema relevância ao abordar o tema "inclusão", lembrarmos da mulher, mas também da mãe, principalmente as que amamentam os seus filhos. Atualmente as empresas que não desenvolverem estratégias para acolher, dialogar e flexibilizar para essas mães, sem dúvidas correm o risco de perder grandes

talentos, que poderiam contribuir de forma ímpar para a organização, seja ela pública ou privada, além de ser vista como uma empresa que não valoriza seus colaboradores. Vale ressaltar que a Organização Pan-Americana da Saúde/Organização Mundial da Saúde (OPAS/OMS) recomenda iniciar a amamentação nos primeiros 60 minutos de vida, assim como o aleitamento materno como forma exclusiva de alimentação até os seis meses de idade e, de maneira completar, até os dois anos.

Atualmente, apenas $38 \%$ dos bebês são alimentos exclusivamente com leite materno até os seis meses na região das Américas e só $32 \%$ continuam amamentando até os 24 meses. O aleitamento materno é vital para a saúde e desenvolvimentos das crianças ao longo de toda a vida

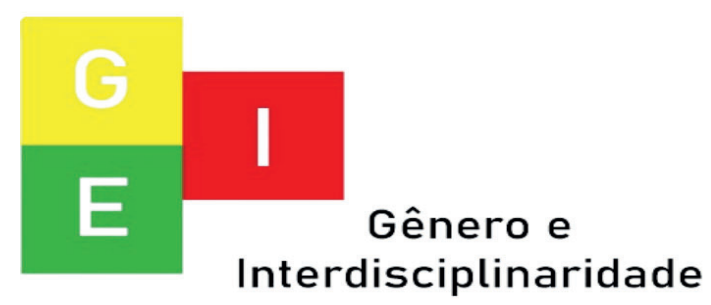


ISSN: 2675-7451

Vol. 02 - n 03 - ano 2021

Editora Acadêmica Periodicojs

e reduz os custos para os sistemas de saúde, famílias e governo. Além da redução do risco de câncer de mama nas mães.

A diversidade é um conceito que está ligado ao respeito à variedade de atributos de indivíduos e grupos. Dentro das organizações, a diversidade surge para trazer a minoria para dentro do ambiente que historicamente pertence à maioria. Uma vez que consigamos entender o verdadeiro sentido das políticas de diversidade, estaremos contribuindo não só para uma organização melhor, mas para uma sociedade mais inclusiva.

\section{METODOLOGIA}

Pesquisa bibliográfica através de Análise de literatura de artigos e outros textos.

CONSIDERAÇÕES FINAIS
Com o intuito de desen-

volver uma linguagem conceitual de forma clara e no que significa o termo "diversidade", é preciso, antes de começar, estruturar o próprio conceito. "Há diversos aspectos a serem considerados ao se pensar no que significa diversidade: sexo, idade, grau de instrução, grupo étnico, religião, origem, raça e língua". A diversidade é um mix de pessoas com identidades diferentes interagindo no mesmo sistema social conforme cita (Fleury, 2000).

Existem outras definições, mais amplas da diversidade, como a de (Thomas, 1991) que afirmou que: "A diversidade inclui todos, não é algo que seja definido por raça ou gênero. Estende-se a idade, história pessoal e corporativa, formação educacional, função e personalidade. Inclui estilo de vida, preferência

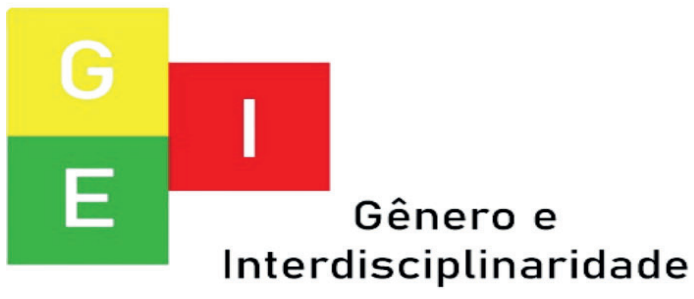


ISSN: 2675-7451

Vol. 02 - n 03 - ano 2021

Editora Acadêmica Periodicojs

sexual, origem geográfica, tempo de serviço na organização, status de privilégio ou de não-privilégio e administração ou não administração". Logo, de maneira objetiva, a diversidade quando tratada no âmbito social - é o termo que representa a existência de um grande conjunto de variadas características humanas coexistindo em um mesmo ambiente.

A diversidade está presente em todos os âmbitos, sejam eles organizacionais ou não, e, mesmo dentro de uma organização onde o principal objetivo é o lucro, as ações voltadas à gestão de diversidade devem reconhecer que cada elemento é único e insubstituível, sendo as pessoas o foco mais importante dentro da organização.

Muitas empresas têm procurado adotar práticas de gestão da diversidade, no sentido de formar e administrar equipes heterogêneas, ou seja, equipes diversificadas em termos tanto biográficos - como gênero e idade -, quanto subjetivos - como personalidade, educação e valores. A necessidade de administrar a diversidade organizacional foi um desdobramento da diversificação crescente da força de trabalho para (Fleury, 2000).

(Mendes, 2005) elenca

alguns motivos que elevaram a importância da diversidade nas organizações e, consequentemente, trouxeram o tema à pauta das estratégias organizacionais, tais quais, legislações decorrentes de mobilizações sociais, globalização das empresas, migrações em busca de emprego em países mais desenvolvidos, estruturas de trabalho multifuncionais e políticas de responsabilidade social corporativa.

De acordo com (Rob-

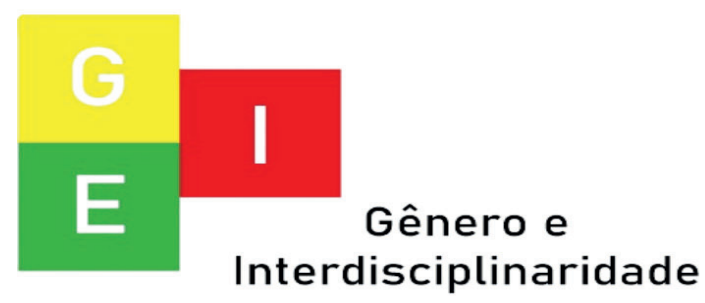


ISSN: 2675-7451

Vol. 02 - n 03 - ano 2021

Editora Acadêmica Periodicojs

bins et.al., 2010) a diversidade em nível profundo é constituída por elementos subjetivos, como personalidade, habilidade e valores. Conforme as pessoas se conhecem, passam a dar mais valor a estas características, em detrimento das características biográficas. Seguindo a mesma linha conceitual (Horvitz, 2007) entende a diversidade em nível profundo como a junção de todos os aspectos relacionados à realização de tarefas. Os atributos pessoais, como educação, cultura, cargo e especialização, têm um peso maior na maneira de realizar tarefas em comparação às características biodemográficas.

De acordo com (Fleury, 2000) a gestão da diversidade foi um desdobramento do aumento da diversificação da mão de obra e da busca por maiores vantagens competitivas. Aquino (Alves et.al, 2004) ratificam esse conceito, ao afirmar que gerenciar a diversidade empresarial, ou seja, buscar, através de práticas empresariais, a formação de equipes compostas por membros com distintas experiências e habilidades, é uma estratégia organizacional voltada para a busca de vantagem e diferenciação no mercado. Coutinho também relaciona a gestão da diversidade cultural à esta busca: As empresas brasileiras vêm buscando implementar políticas que tragam resultados positivos e maiores retornos a seus acionistas. Muitas dessas empresas buscam cada vez mais utilizar sua força de trabalho como diferencial competitivo, não somente para justificar uma empresa que seja socialmente responsável ou que tenha políticas compensatórias, o que pode ser identificado como diferencial no mercado, mas também trabalhando com a diferença cultural

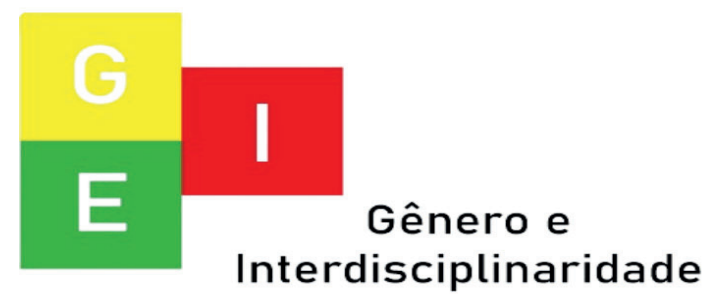


ISSN: 2675-7451

Vol. 02 - n 03 - ano 2021

Editora Acadêmica Periodicojs

de seus colaboradores como uma vantagem competitiva significativa. Nesse espírito está colocada uma das novas tendências no mercado que é a Gestão da Diversidade Cultural.

Acredito que se as organizações tanto públicas quanto privadas, investirem em políticas e boas práticas visando o acolhimento, o bem estar do colaborador, valorizando o seu potencial e talentos, sem discriminação e de forma justa, incentivando a realização de treinamentos e aprimoramentos contínuos, melhorando o salário, pagando o décimo terceiro, oferecendo bônus pelo seu desempenho dentro da empresa, flexibilizando a carga horária de trabalho, implantando novas políticas para acolher as mães, principalmente as lactantes, pensando em primeiro lugar nas pessoas e como consequencia a empresa terá grandes possibilidades de manter as pessoas talentosas, contribuindo para o sucesso da mesma.

\section{REFERÊNCIAS BIBLIO- GRÁFICAS}

Barreiro, J., Nabosne, I., Menezes, R. \& Matsumoto, A. (2015). Diversidades nas organizações: Uma análise de Resultados. Congresso Nacional de excelência em gestão ISSN 1984 - 9354. Brasil. Fernandez, J. (2014). Determinantes culturais da saúde: Uma abordagem para a promoção de equidade. Universidade de São Paulo. Associação Paulista de saúde pública SP. Brasil.

Garcia, W. (2018). Comunicação, diversidade e educação. Observatório da diversidade cultural, Brasil. V78, n.03.2018 - Maio/ junho 2018. ISSN $2526-7442$.

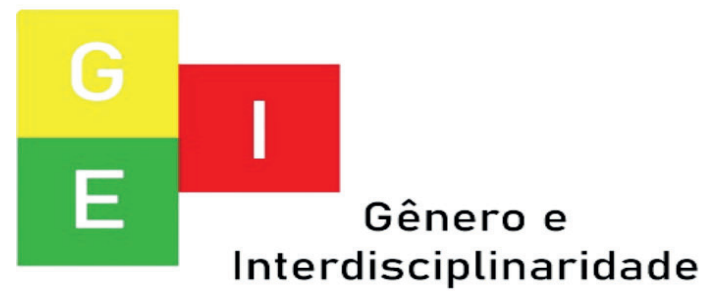


Martins, V. (2019). Gestão da diversidade nas organizações. UFSC. Brasil.

Organização PAM Americana de Saúde (OPAS) Brasil (2018). Aleitamento materno. Brasília, DF, Brasil.

Saraíva, L. \& Irigary, A. (2009). Políticas de diversidades nas organizações: Uma questão de discurso? São Paulo SP, Brasil. Rev. Adm. Empres. Vol. 49 no. 3.

Rambo, R. \& Diehl, L. (2015). Diversidade Cultural e seus impactos na prática profissional, Brasil. Estudo e debate, Lajeado, V.22, n.1, p.97 - 115 2015. ISSN 1983-036x.

Santos, J. \& Santana, A. (2017).

Diversidade nas organizações: Inclusão Social ou estratégia competitiva? Universidade Fede- ral de Pernambuco, Brasil.

Souza, V. (2018). Diversidade cultural e educação ensaio para além dos muros. Observatório da diversidade cultural, Brasil. V78, n.03.2018 - Maio/junho 2018. ISSN $2526-7442$.

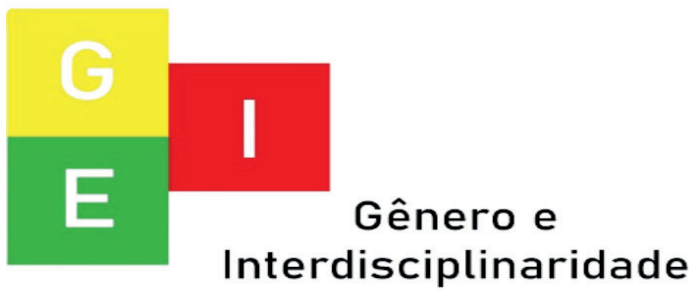

